\title{
EN TORNO A LA POLITICA REVISIONISTA DE FELIPE V: LOS FLETAMENTOS DE BUQUES EXTRANJEROS EN EL PUERTO DE ALICANTE Y SU EMPLEO EN LA EXPEDICION A SICILIA DEL AÑO 1718
}

\author{
Armando ALBEROLA ROMA \\ Universidad de Alicante
}

En un trabajo anterior ya aludí a las cuestiones relativas al proceso de reorganización de la armada española llevadas a cabo en los años iniciales del reinado del primer borbón, así como al papel desempeñado por el puerto de Alicante en la reconquista de Orán'. Fundamentalmente llamaba la atención sobre el empleo del contrato de fletamento como argucia legal que, en la práctica, enmascaraba una requisa de buques con pabellón extranjero. Si en la década de los treinta del siglo XVIII el volumen de fletamentos es bien significativo, máxime una vez cubiertos los objetivos bélicos de la toma de Orán, en los años clave del desarrollo de la política italiana -momento en que las carencias navales eran ostensibles- el recurso a este contrato se revelaba imprescindible para afrontar las necesidades derivadas del transporte de soldados, armas, municiones y provisiones.

El presente artículo proporciona una muestra de ese empleo del secuestro de embarcaciones puesto en práctica en el puerto de Alicante al objeto de destinarlas a la expedición contra Sicilia; actividad a la que no fue ajeno, obviamente, el resto del litoral mediterráneo español. No es este el lugar más adecuado para efectuar una descripción minuciosa de la situación política del momento, a pocos años de la firma de los tratados de Utrech-Rastatt que tan lesivos habían resultado para el patrimonio territorial de la monarquía hispánica²;

1 A. ALBEROLA ROMA', A.: "El port d'Alacant en la política mediterrània de Felip V: la reconquesta d'Orá (1732), en Homenatge al Doctor Sebastià García Martínez. Consellería de Cultura, Educació i Ciéncia de la Generalitat Valenciana. València, 1988. Volumen II, pp. 282-297. Un complemento de este trabajo, bajo el título de "La expedición contra Orán del año 1732. El embarque de tropas por el puerto de Alicante, se halla actualmente en prensa y próximo a publicar por el Ayuntamiento de Alicante.

2 Descripción que, con mucha mayor autoridad, han realizado entre otros: A. BETHENCOURT MASSIEU: Patiño en la política internacional de Felipe V. Valladolid, 1954. J.M. JOVER ZAMORA: Política mediterránea y política atlántica en la España de Feijóo. Oviedo, 1956. C. SECO SERRANO: "Estudio preliminar" a la obra del marqués de San Felipe citada líneas más abajo. Un excelente resumen nos lo ofrece D. OZZANAM: "La política exterior de españa en tiempos de Felipe V y Fernando VI", en J. M. JOVER 
no obstante sí que cabe traer a colación que durante los primeros años del reinado de Felipe $\mathrm{V}$ se asistió al despliegue de una agresiva política tendente a recuperar esas posesiones perdidas tras la Guerra de Sucesión, fundamentalmente las italianas. Política cuyo alcance y contenido no cabe reducir a las pretensiones maternales de Isabel de Farnesio en connivencia con el cardenal Alberoni y las conexiones parmesanas, puesto que el propio Felipe V también desempeñó su papel en el diseño de la misma, alumbrando lo que se ha dado en llamar el "revisionismo" o "irredentismo" mediterráneo ${ }^{3}$. Es innegable la labor de Giulio Alberoni a la hora de establecer las prioridades diplomáticas ${ }^{4}$ de la misma manera que no se debe obviar la atención prestada desde el gobierno a la maltrecha flota española ${ }^{5}$ y los medios puestos para hacer posible su relanzamiento y recuperación. Y aquí el papel de José Patiño, futuro Secretario de Hacienda y de Marina e Indias, resultó fundamental, pues desde 1713 ya manifestaba sus preocupaciones por la renovación de la flota, alentando la construcción de barcos y dando ciertas facilidades para la tala y transporte de madera ${ }^{6}$.

En el horizonte de todo ello estaba la recuperación de las plazas italianas en manos imperiales tras los tratados de Utrech, y hacia ese objetivo encaminó sus afanes el cardenal Alberoni secundado por Patiño. En poco tiempo se consiguió armar una flota que, partiendo de Barcelona, desembarcó en Cerdeña y ocupó la isla en agosto de $1717^{7}$. El éxito espoleó los ánimos de los monarcas y del propio Alberoni quien, pese a los consejos pruden-

\section{Cont.}

(dir): La época de los primeros borbones. La nueva monarquía y su posición en Europa (1700-1759). Madrid, 1985, pp. 457 y ss. Más recientemente, J.M. OLIVA MELGAR: "Del revisionismo de Utrech al período revolucionario", en A. DOMíNGUEZ ORTIZ (dir): El reformismo borbónico (1700-1789). Barcelona, 1989 , pp. 322 y ss. Por supuesto no se pueden obviar las valiosas, y minuciosas, referencias que efectúan los contemporáneos o las contenidas en las obras más clásicas. En este sentido resulta, hoy por hoy, imprescindible la consulta de V. BACALLAR DE SANNA, MARQUÉS DE SAN FELIPE: Comentarios de la guerra de España e historia de su rey Felipe $V$, el animoso. Biblioteca de Autores de España. Tomo XCIX. Madrid, 1957. N. de J. BELANDO: Historia civil de España, sucesso de la guerra y tratados de paz desde el año 1700 hasta el de 1733. Madrid, 1740. G. COXE: España bajo el reinado de la casa de Borbón. Desde 1700 en que subió al trono Felipe $V$ hasta la muerte de Carlos $I V$ acaecida en 1788. Escrita en inglés por - y traducida al español con notas, observaciones y un apéndice por D. Jacinto de Sala y Quiroga. Est. Tipográfico de D. F. de P. Mellado. Madrid, 1846. Fundamentalmente el volumen II.

3 C. SECO SERRANO: "Estudio preliminar" a los Comentarios de la guerra de España ..., pp. XXIIXXIII. A. DOMíNGUEZ ORTIZ: Sociedad y Estado en el siglo XVIII español. Barcelona, 1976, pp. 55-56.

4 En torno a la figura de Alberoni ver F. VALSECCCHI: "La política italiana de Alberoni. Aspectos y problemas", en Cuadernos de Investigación Histórica, 2 (1978), pp. 479-492.

5 Respecto de los problemas de la marina española ver la obra clásica de C. FERNANDEZ DURO: La Armada española. Madrid, 1895-1903, 9 vols (reed. del Museo Naval. Madrid, 1972-1973). Igualmente ver G. WALKER: Politica española y comercio colonial (1700-1789). Barcelona, 1979. P.E. PÉREZ MALLAÍNA: Política naval española en el Atlántico. 1700-1715. Sevilla, 1982. J.P. MERINO NAVARRO: La Armada española en el siglo XVIII. Madrid, 1981.

6 Archivo General de Simancas. Guerra Moderna. Suplementos, legajo 561.

7 M. A. ALONSO AGUILERA: La conquista y el dominio español de Cerdeña (1717-1720). Introducción a la política española en el Mediterráneo posterior a la Paz de Utrech. Serie "Estudios y Documentos". Valladolid, 1977. $137 \mathrm{pp}$. 
tes de Patiño, no pudo resistirse a la salida inmediata de una nueva expedición, esta vez con destino a Sicilia, un año después ${ }^{8}$. Las peripecias para reunir esta segunda flota son narradas por los contemporáneos y los historiadores clásicos. Todos ellos coinciden en señalar que se apeló al patriotismo y se ofrecieron donativos voluntarios y generosos al gobierno, no regateándose recursos ${ }^{9}$ con el fin de componer la armada. Ésta, bajo el mando del almirante don Antonio Gaztañeta "buen piloto, pero poco experimentado en la guerra" al decir del marqués de San Felipe ${ }^{10}$, zarpó del puerto de Barcelona el 18 de junio de 1718 dispuesta a reconquistar Sicilia. Existen ciertas divergencias en cuanto a las cifras absolutas del contingente armado, aunque nadie niega lo imponente de la misma máxime si se tiene en cuenta el escaso tiempo con que se había contado para su preparación ${ }^{11}$. Una parte importante de las embarcaciones que componían la expedición, aquéllas dedicadas al transporte, es objeto de atención en este artículo ya que fueron embargadas por la Corona a instancias de José Patiño para que pudieran desempeñar esta misión. El puerto de Alicante fue uno de los lugares donde se llevó a cabo esta actividad y sus principales objetivos resultaron ser los navíos con pabellón extranjero que solían recalar en estas aguas.

\section{LAS REQUISAS DE BUQUES EN LAS COSTAS LEVANTINAS:}

\section{EL PAPEL DE ALICANTE}

La puesta en marcha de la operación planeada por Patiño a instancias del cardenal Alberoni, exigía disponer del mayor número posible de embarcaciones que pudieran destinarse al transporte de tropas y bastimentos e incluso, llegado el caso, que hasta entraran en combate. Es por ello que el fletamento o arrendamiento de barcos, fundamentalmente extranjeros, se convirtió en el recurso más socorrido y eficaz para componer la escuadra de la que, por aquel entonces, carecía la monarquía hispánica y a cuya reconstrucción dedicaba sus afanes don José Patiño. Y este mecanismo legal, que en la práctica no hacía más que disimular una requisa pura y dura, tras ser utilizado con éxito en 1717 en la empresa sarda

8 El marqués de San Felipe es suficientemente explícito al afirmar que "amó tanto su propio empeño el cardenal, que no supo desistir de él; y fiando, como decía, gran parte de la obra a la fortuna, mandó que juntándose en Barcelona tropas y naves que en toda España había prevenido, entregando dos pliegos sellados a los comandantes, hizo partir esta armada el día 18 de junio". Comentarios ..., pág. 284.

9 Coxe, por ejemplo, señala: "compráronse naves y municiones navales en donde quiera que se hallaron, apresáronse los buques neutros para los transportes (...)", España bajo el reinado ..., pág. 219.

10 V. BACALLAR DE SANNA: Comentarios ..., pág. 284.

(11) Coxe sigue en su descripeión al marqués de San Felipe, y éste menciona a un cuerpo expedicionario cercano a los 30.000 hombres muy bien pertrechados al mando de don Juan Francisco de Vete, marqués de Lete; que habían sido trasladados en más de 340 embarcaciones que escoltaba un fuerza naval de guerra que superaba los 35 buques. En relación con el aspecto del contingente naval el propio marqués de San Felipe señala "nunca se había visto armada mas bien abastecida (...) y ya escarmentados de lo que en Cerdeña había sucedido traían 155.000 fajinas y 500.000 piquetes para las trincheras; se pusieron víveres para todo este armamento para cuatro meses", Ibidem. 
sería empleado con asiduidad en posteriores expediciones habida cuenta el excelente resultado que siempre proporcionó ${ }^{12}$.

El seguimiento minucioso de la febril actividad fletadora observada en las costas mediterráneas durante los primeros meses del año 1718 puede efectuarse, para el caso de Alicante, gracias a la consulta exhaustiva de los protocolos notariales conservados en el Archivo Histórico Provincial. De ellos, las series relativas a los escribanos Francisco Andújar y Antonio García ofecen un total de cincuenta y ocho escrituras de fletamento de buques con destino a la expedición siciliana suscritas entre los meses de enero y mayo de 1718; amén de otro tipo de documentación complementaria, pero de sumo interés, como es la relativa a otorgamiento de poderes por parte de los capitanes y patrones de los diferentes navíos para hacer efectivo el cobro de los fletes concertados y, en su caso, de las correspondientes indemnizaciones ${ }^{13}$. El número de navíos fletados frente a las costas alicantinas es ciertamenmte significativo; máxime si tomamos en consideración los datos que proporciona Mercader Riba para Cataluña, en los cuales escasean las referencias a fletamentos efectuados en la propia ciudad de Barcelona, a diferencia de lo acaecido en la expedición del año anterior a Cerdeña ${ }^{14}$.

El papel desempeñado por Alicante en 1718 con motivo de la empresa militar contra Sicilia es un claro precedente del que, años más tarde, tornaría a asumir la ciudad como consecuencia de la organización del embarque de la expedición que, partiendo de su puerto, recuperaría la plaza norteafricana de Orán ${ }^{15}$. No obstante, en el caso que nos ocupa, la rada alicantina sirvió de base previa de reunión de todas las embarcaciones fletadas in situ

12 En relación con los navíos fletados para hacer frente a las necesidades de la expedición a Cerdeña, ver J. MERCADER RIBA: Felip V i Catalunya. Barcelona, 1985 (2a edic.), pp. 217 y ss. Respecto de los avatares acaecido en torno a la misma expedición sigue resultando imprescindible la consulta de la obra de M.A. ALONSO AGUILERA: La conquista y el dominio español de Cerdeña (1717-1720). Introducción a la política española en el Mediterráneo posterior a la Paz de Utrech. Serie "Estudios y Documentos". Departamento de Historia Moderna. Valladolid, 1977. 137 pp. Por lo que hace a empresas posteriores, como la reconquista de Orán, ver A. ALBEROLA ROMA': "El port d' Alacant en la política mediterrània ...

13 Archivo Histórico Provincial de Alicante (en adelante AHPA). Protocolos notariales de Francisco Andújar, $\mathrm{P} / 65$ y P/68. Protocolos notariales de Antonio Garcia, $\mathrm{P} / 783$ y P/785.

14 Mercader Riba indica que en las fechas previas a la partida hacia Sicilia tan sólo se tiene constancia de cinco fletamentos, y uno de ellos fue signado precisamente en Alicante por el capitán francés Juan Bautista Brive o Brina; cifr. en Felip V $i$ Catalunya, pág. 221 (de este fletamento tenemos constancia en AHPA, Protocolos notariales de Francisco Andújar, P/65, ff. 68-69v). Ello no quiere decir que en el resto de la costa catalana y valenciana no se produjeran las necesarias requisas, pero al menos cobra cierta significación el hecho de que entre las cerca de 250 naves de transporte fletadas, 58 lo hubieran sido en la ciudad de Alicante. En ello pudo influir la abundancia de embarcaciones que arribaban dada la dilatada trayectoria comercial de la urbe alicantina, la capacidad del puerto, sus favorables condiciones naturales e, incluso, la existencia de colonias de comerciantes extranjeros que, llegado el caso, actuaron como intérpretes y representantes de sus compatriotas víctimas del embargo de su navío.

15 A. ALBEROLA ROMA': "El port d' Alacant ...". Alicante fue asimismo punto de destino de las tropas evacuadas de Cerdeña a fines de agosto de 1720, una vez confirmado el abandono de la isla tras la entrada de España en la Cuádruple Alianza; cifr. en M.A. ALONSO AGUILERA: La conquista y el dominio español de Cerdeña ..., pp. 129-131. 
o en enclaves próximos, como Cartagena, y que con posterioridad se trasladaron al puerto de Barcelona, auténtico punto de salida de la flota con destino a Sicilia.

En todos los casos analizados la escritura de fletamento es sumamente minuciosa, guardando grandes similitudes de contenido respecto de las observadas por Mercader Riba para el área de Cataluña. No obstante, el destino del navío objeto del fletamento permanece invariablemente en secreto, remitiendo la información al dato vago de que aquél será empleado "en el Real Servicio" durante el tiempo que se estime necesario por los responsables de la expedición ${ }^{16}$. Como fletador figura en todos los casos don Francisco Driguet, nombrado por Patiño responsable para organizar desde Alicante los detalles relativos a la requisa de buques destinados a la conquista de Sicilia ${ }^{17}$.

Al margen de ello, la escritura proporciona detalles de sumo interés tales como el nombre del barco, su nacionalidad, tipología y tonelaje, el número de tripulantes, las características del armamento que porta, así como el nombre de su capitán o patrón. Junto a ellos, el documento se detiene en especificar de manera exahustiva las condiciones del fletamento y el importe del flete. En ese sentido, y tras dejar sentado que la embarcación es fletada para el Real Servicio por tiempo indefinido, se establece un pago mensual por anticipado a razón de tres pesos por tonelada de arqueo así como la entrega por una sola vez de la denominada capa, cantidad que representaba el $10 \%$ del pago mensual. Esta cantidad se hacía efectiva, junto con la correspondiente a la primera mensualidad, en el momento de la firma del contrato y, habitualmente, el capitán del navío fletado hace constar haber recibido dicho pago de manos del Tesorero de Guerra de la plaza alicantina. Si el navío era portador de mercancías con destino a otros puertos, corría por cuenta de la Real Hacienda el pago de los gastos de desembarco de aquéllas así como la compensación por las pérdidas ocasionadas. En el momento de la firma se fijaba asimismo, una vez conocido el justiprecio correspondiente, la indemnización a percibir en caso de que el navío se perdiera. Igualmente se especificaba que la embarcación no pagaría derechos de atraque en ningún puerto mientras permaneciera al servicio de la Corona. El capitán del navío, por su parte, garantizaba que el mismo estaba en perfecto estado de conservación, "sano, estanco de quilla y costado, prevenido y dispuesto de las xarcias y en toda forma para hacer el servicio".

Respecto a la nacionalidad de las embarcaciones requisadas cabe decir que el mayor número corresponde a las de origen inglés, pese a la conocida oposición del gobierno británi-

I6 Hay una única excepción: la urca francesa "San Nicolás", de 650 toneladas, es fletada el día 6 de marzo de 1718 por espacio de cuatro meses con la misión expresa de hacer viajes entre Cádiz y Cataluña, prestar servicio a las tropas de su magestad a la vez que transportar árboles y pertrechos; cifr. en AHPA, Protocolos notariales de Antonio García, P/785, ff. 47-48v.

17 El propio Francisco Driguet se autoproclama "director de la expedición", por designación de Patiño, en una Declaración contenida en AHPA, Protocolos notariales de Antonio García, P/65, ff. 82-82v. También hacen constar este cargo buena parte de los capitanes de navíos embargados. En ese sentido, y entre otras muchas más, sirve la referencia de Pedro Sandourne, capitán del navío francés "San Francisco", quien tras serle confiscado éste en Cartagena se vio obligado a personarse en Alicante para discutir el flete ante don Francisco Driguet "director para la presente expedición que se halla en esta ziudad nombrado por el Sr.don Joseph Patiño del Consejo de S. M., Intendente General de la Marina de España"; cifr. en AHPA. Protocolos notariales de Francisco Andújar, P/68, ff. 54-55v. 
co a los planes bélicos españoles y la firme negativa de los propios capitanes de estos buques que, en todos los casos, hacen constar sus protestas por escrito en el momento de la firma del contrato. Las tradicionales relaciones del puerto alicantino con el norte europeo, la importancia del comercio del salazón y el papel que como enclave redistribuidor de este producto desempeñaba Alicante, justificaban en buena medida la gran presencia de navíos británicos en estas costas así como la lógica actuación requisadora desplegada contra ellos $^{18}$. Los barcos de nacionalidad francesa fletados suponen también un número considerable aunque inferior al de los ingleses y sin ofrecer las dificultades y resistencias de éstos; antes bien parece deducirse la buena predisposición de sus capitanes a navegar por cuenta del Real Servicio tal y como se detecta en Cataluña ${ }^{19}$. Barcos genoveses únicamente se cuentan dos, y la presencia de embarcaciones locales es nula, a diferencia de lo observado para Cataluña por Mercader Riba ${ }^{20}$.

Por lo que hace a la tipología de las embarcaciones fletadas el predominio de los navíos es aplastante. Conceptuados a partir del siglo XVI como barcos de tonelaje superior a las 500 toneladas, de grandes dimensiones y especialmente dedicados a las empresas bélicas, no parecen encajar plenamente estas características con las de los "navios" fletados en Alicante ya que sus tonelajes oscilan entre las 99 y las 634 toneladas. Quizá por ello convendría efectuar una depuración de los datos, lo cual reduciría de manera notable las unidades correspondientes a esta tipología. Pensamos que eso no es en absoluto problemático, por cuanto se dispone de los datos concretos de tonelaje de cada embarcación. Por ello hemos respetado la definición del protocolo, pese a extrañarnos en ocasiones la consideración de navío para un barco que tan sólo desplaza 100 toneladas. En cualquier caso queda fuera de duda la preferencia por este tipo de embarcación a la hora de la requisa. Las urcas, barcos de origen neerlandés, con popa redondeada y gran anchura en el centro, dotados de gran capacidad de carga aunque muy lentos y pesados, también tienen representación, aunque escasa, en los fletamentos. Por último, las embarcaciones plenamente mediterráneas significan un pequeño porcentaje del total, tratándose fundamentalmente de tartanas, pingues, galeras y una barca.

18 Respecto a las características del puerto de Alicante durante el Setecientos, resulta imprescindible la consulta de E. GIMÉNEZ LóPEZ: Alicante en el siglo XVIII. Economía de una ciudad portuaria del Antiguo Régimen. Institución Alfonso el Magnánimo. Valencia, 1981. Mercader Riba refiere la oposición de los capitanes ingleses a prestarse al flete de sus barcos, Felip V $i$ Catalunya, pp. 220-221.

19 J. MERCADER RIBA: Felip $V$ i Catalunya, pp. 218-221.

20 lbidem. 


\section{TIPOLOGIA NA C I O A L I D A D TOTAL TONELA.JE MEDIO Francesa Inglesa Genovesa}

\begin{tabular}{lrrrrc}
\hline Navío & 12 & 31 & 2 & 45 & 268,2 \\
Urca & 1 & 1 & - & 2 & 575 \\
Galera & - & 2 & - & 2 & 219 \\
Tartana & 6 & - & - & 6 & 57 \\
Pingue & 2 & - & - & 2 & 90,5 \\
Barca & 1 & - & - & 1 & 142 \\
\hline TOTALES & 22 & 34 & 2 & 58 & $1.352,7$
\end{tabular}

\section{CUADRO I.- TOTAL DE EMBARCACIONES FLETADAS EN EL PUERTO DE ALICANTE CON DESTINO A SICILIA (1718)}

Fuente: AHPA. Protocolos notariales de Francisco Andújar y Antonio García. Elaboración propia. El resto de cuadros que aparecen en el artículo proceden de idéntica fuente, por lo que en adelante se obvia su referencia.

Este resumen general permite, no obstante, un desglose mucho más exhaustivo en el que se puede detallar, uno por uno, todos los componentes del contingente expedicionario, a la vez que valorar el número de tripulantes y la capacidad de fuego.

Las 58 embarcaciones fletadas por don Francisco Driguet en Alicante por cuenta del Real Servicio componían una flota que desplazaba un total de 14.326 toneladas, de las cuales cerca de 8.000 correspondían a los barcos de nacionalidad inglesa, los más numerosos aunque no los de mayor peso y dotación. Individualizando esta cuestión, los barcos de más elevado porte eran la urca francesa "San Nicolás", de 650 toneladas; los navíos, igualmente franceses, denominados "San Nicolás" (634 Tm.), "San Francisco" (613 Tm.) y "San Antonio" (608 Tm.); la urca inglesa "Shrewbury" (500 Tm.) y el navío de idéntica nacionalidad "Mediterráneo" (400 Tm.). En el resto de las embarcaciones predominan los valores comprendidos entre las 150 y las 300 toneladas de arqueo, destacando el navío genovés "Santiago" con 357 toneladas y 38 hombres, una de las tripulaciones más numerosas de todos los fletados. A otro nivel cabe considerar las embarcaciones típicamente mediterráneas que, excepción hecha de dos galeras inglesas ${ }^{21}$, todas ellas andan por debajo de las 100 toneladas, cosa absolutamente lógica por tratarse -en el caso de las tartanas- de embarcaciones menores utilizadas habitualmente para la pesca y el cabotaje y transformadas en vehículo de transporte de tropas en esta ocasión ${ }^{22}$. Ello justificaría, igualmente, la ausencia de artillería en las mismas.

21 Se trata de las galeras "La deseada" y "Elton", de 213 y 225 toneladas respectivamente, capitaneadas por Arthur Ballard y Juan Hall.

22 Las cifras manejadas por Cesáreo FERNANDEZ DURO en La Armada española, Madrid, 1900, vol. VI, pág. 140, aluden a 123 tartanas como integrantes del convoy que acompañaba a los navíos propiamente de guerra. 
En cuanto al número total de tripulantes, éste asciende a 1.067 hombres lo que viene a representar una media de 18 tripulantes por embarcación. El mayor contingente de hombres se corresponde con los barcos de nacionalidad inglesa, al ser éstos los más numerosos y los que más toneladas en conjunto desplazan. No obstante las tripulaciones más nutridas son las de los navíos franceses "El Fénix", con 47 hombres, y el "San Juan Bautista" con 38 , idéntico número de hombres que llevaba a bordo también el navío genovés "Santiago".

Capítulo interesante dentro de estas reflexiones lo constituye el relativo al armamento existente en cada buque, una vez comprobado que todos ellos van artillados lo cual marca una diferencia notable respecto de los fletamentos efectuados para la precedente expedición de Cerdeña ${ }^{23}$. Es obvio que la mayor parte de estos buques tenía misiones de transporte de tropas y bastimentos, pero el hecho de que además dispusieran de cierta capacidad de fuego viene a confirmar el cambio cualitativo experimentado en la situación general del Mediterráneo; cambio por otra parte temido por Alberoni y Patiño ${ }^{24}$. Las referencias de los contemporáneos, pese a pequeñas divergencias a la hora de cuantificar en su totalidad el poderío de la escuadra española con rumbo a Sicilia, subrayan el hecho de que, junto a los más de 30.000 soldados, se transportaran 100 piezas de artillería de asalto y 25 de campaña, 40 morteros, amén de de 100.000 proyectiles, 30.000 bombas y 20.000 quintales de pólvora ${ }^{25}$. Por ello quizá resulte significativo el hecho de que las embarcaciones embargadas en Alicante, todas ellas mercantes a juzgar por lo descrito en los protocolos acerca de la carga portada y de sus destinos, alinearan en conjunto 512 cañones de los que no se especifica calibre, 34 pedreros $^{26}$, así como lo que los documentos califican ambiguamente como "armamento diverso" sin entrar en más detalles, aunque cabría pensar que se trataría de armas ligeras de uso individual. Es presumible que estos navíos artillados tuvieran más bien una actitud autodefensiva durante el transcurso de la travesía antes que misiones estrictamente ofensivas, las cuales, en su caso quedarían reservadas a la hora del desembarco en la isla.

Los cuadros que se acompañan ofrecen las características a que nos acabamos de referir atendiendo a las diferentes nacionalidades de origen.

23 J. MERCADER RIBA: Felip V i Catalunya, pág. 220.

24 Resulta suficientemente significativa en ese sentido la partida de la flota inglesa al mando del almirante Bingg, casi coincidente en el tiempo con la de la española hacia Sicilia, rumbo al Mediterráneo con el fin de hacer respetar las cláusulas de Utrech.

25 Ver, en ese sentido, entre otros, a BACALLAR DE SANNA, V.: Comentarios de la guerra de España.., pág. 284; COXE, G.: España bajo el reinado de la casa de Borbón ..., pág. 234. C. FERNANDEZ DURO: La Armada Española, vol. VI, pág. 140.

$26 \mathrm{El}$ pedrero era una pieza de tiro curvo que lanzaba proyectiles de piedra tallada. Se la considera precursora del mortero.. 


\begin{tabular}{|c|c|c|c|c|c|}
\hline \multirow[t]{2}{*}{ NOMBRE } & \multirow{2}{*}{$\begin{array}{l}\text { TONELAJE } \\
\text { (Tm) }\end{array}$} & \multirow[t]{2}{*}{ TRIPULANTES } & \multicolumn{3}{|c|}{ ARMAMENTO } \\
\hline & & & $\mathrm{C}$ & $\mathbf{P}$ & $\mathbf{D}$ \\
\hline San Francisco & 613 & 30 & 18 & - & sí \\
\hline El Fénix & 342 & 47 & 20 & - & - \\
\hline San Antonio & 608 & 27 & 3 & - & - \\
\hline San Miguel & 338 & 30 & 16 & - & - \\
\hline La Francisca de Alicante & 230 & 38 & 12 & - & - \\
\hline La Esperanza & 152 & 18 & 10 & - & - \\
\hline San Nicolás & 634 & 28 & 14 & - & - \\
\hline San Juan Evangelista & 188 & 18 & 2 & 10 & - \\
\hline El Constante & 256 & 27 & 8 & - & - \\
\hline San Juan & 314 & 28 & 12 & - & sí \\
\hline Santa María de la Guarda & 491 & 22 & 8 & - & - \\
\hline San Juan Bautista & 348 & 38 & 14 & - & - \\
\hline TOTALES & 4.514 & 351 & 137 & 10 & \\
\hline
\end{tabular}

CUADRO II.- NAVIOS FRANCESES FLETADOS EN ALICANTE CON DESTINO A SICILIA (1718)

Claves. $-\mathrm{C}=$ cañones, $\mathrm{P}=$ pedreros, $\mathrm{D}=$ armas diversas 


\begin{tabular}{|c|c|c|c|c|c|}
\hline NOM B R E & TONELAJE & TRIPULANTES & A I & $\mathbf{M}$ & T 0 \\
\hline & (Tm) & & $\mathrm{C}$ & $\mathbf{P}$ & D \\
\hline Kesia & 235 & 18 & 12 & - & - \\
\hline $\mathrm{LaPaz}$ & 303 & 18 & 6 & - & - \\
\hline Ana & 175 & 11 & 9 & - & - \\
\hline La Galera de Florencia & 193 & 15 & 12 & - & - \\
\hline El Príncipe de Gales & 258 & 14 & 8 & - & - \\
\hline Honor & 138 & 10 & 4 & - & - \\
\hline El mercader de Lisboa & 195 & 14 & 8 & - & - \\
\hline La Galera Lyne & 238 & 16 & 10 & - & - \\
\hline Griffon & 174 & 14 & 8 & - & - \\
\hline El mercader de Hamburgo & 234 & 18 & 16 & - & - \\
\hline Leal súbdito & 200 & 16 & 14 & - & sí \\
\hline La galera Sara Gales & 204 & 14 & 4 & - & sí \\
\hline Abraham & 247 & 14 & 10 & - & - \\
\hline Príncipe Jorge & 347 & 34 & 20 & - & - \\
\hline Britannia & 177 & 12 & 6 & - & - \\
\hline Aurengzeb & 252 & 16 & 12 & - & - \\
\hline Bedminster & 232 & 13 & 12 & - & - \\
\hline Burcam & 196 & 14 & 14 & - & - \\
\hline Pedro y Felipe & 326 & 20 & 12 & - & - \\
\hline El Frod & 329 & 16 & 8 & - & - \\
\hline $\mathrm{LaPaz}$ & 116 & 8 & 2 & - & - \\
\hline El pequeño rubí & 99 & 9 & 2 & - & - \\
\hline Hanmore & 99 & 8 & 2 & - & - \\
\hline La María & 282 & 22 & 16 & - & - \\
\hline Plymouth & 280 & 20 & 12 & - & - \\
\hline El Aguila & 308 & 19 & 16 & - & sí \\
\hline Mediterráneo & 400 & 28 & 24 & - & sí \\
\hline La Reina Indiana & 157 & 9 & 4 & - & sí \\
\hline Blake & 185 & 14 & 10 & - & - \\
\hline El Príncipe de Gales II & 212 & 13 & 8 & - & - \\
\hline María Juana & 131 & 8 & 4 & - & - \\
\hline TOTALES & 6.922 & 475 & 305 & & \\
\hline
\end{tabular}

CUADRO III.- NAVIOS INGLESES FLETADOS EN ALICANTE CON DESTINO A SICILIA (1718).

Claves: $\mathrm{C}=$ cañones, $\mathrm{P}=$ pedreros, $\mathrm{D}=$ armas diversas 


\begin{tabular}{lccrrrr}
\hline San Nicolás (F) & urca & 650 & 18 & 14 & - & - \\
Shrewbury (I) & urca & 500 & 22 & 4 & - & - \\
Santiago (G) & navío & 357 & 38 & 20 & - & - \\
N. S. del Rosario (G) & navío & 280 & 27 & 6 & - & - \\
La deseada (I) & galera & 213 & 19 & 10 & - & - \\
Elton (I) & galera & 225 & 18 & 12 & - & - \\
S. Juan Bautista (F) & barca & 142 & 18 & 2 & 10 & sí \\
N.S. Misericordia (F) & pingue & 108 & 16 & 2 & - & - \\
Santa Ana(F) & pingue & 73 & 13 & - & 8 & - \\
S. Juan Bautista (F) & tartana & 58 & 9 & - & - & - \\
San José (F) & tartana & 53 & 8 & - & - & - \\
San Juan (F) & tartana & 65 & 7 & - & - & - \\
El Espíritu Santo (F) & tartana & 58 & 9 & - & - & - \\
San Antonio (F) & tartana & 58 & 10 & - & - & - \\
Santa Isabel (F) & tartana & 50 & 9 & - & 6 & - \\
\hline TOTALES & & 2.890 & 241 & 70 & 24 & \\
\hline
\end{tabular}

\section{CUADRO IV.- RESTANTES EMBARCACIONES FLETADAS EN ALICANTE CON DESTINO A SICILIA (1718)}

*= junto al nombre del barco, y entre paréntesis figura la nacionalidad, la cual responde a las siguientes claves: $\mathrm{F}=$ francesa, $\mathrm{I}=$ inglesa, $\mathrm{G}=$ genovesa. $\mathrm{El}$ resto de claves se corresponden con la de los cuadros anteriores.

\section{EL VALOR DE LOS FLETES Y DE LAS INDEMNINZACIONES}

El análisis de las diferentes escrituras de fletamento objeto de este artículo permite, además de conocer los aspectos puramente bélicos ya reseñados líneas atrás, aproximarnos a cuestiones de muy variada índole tales como la frecuencia de la actividad fletadora o el gasto general de la empresa en lo concerniente a la requisa de los buques, incluído el riesgo de perderlos. Pero no sólo éstas, ya que la detección de problemas algo más cotidianos o domésticos, pero sin duda determinantes en su momento, nos acercan a la realidad de un ambiente prebélico que se pretendía ocultar. Aspectos tales como la necesidad de disponer de intérprete por parte de los diferentes capitanes, el lógico interés por hallar interlocutores frente a la administración española, o la preocupación por el destino inmediato de las mercancías que se hallaban a bordo de cada buque en el momento de su embargo definen, en ocasiones con trazos algo dramáticos, las situaciones vividas.

Los 58 barcos objeto de este comentario fueron requisados o fletados, que tanto da el empleo de uno u otro verbo, por don Francisco Driguet, designado director de la expedi- 
ción en Alicante 27 , aunque en ocasiones existe una instancia previa derivada de la acción embargadora de don José Antonio Chaves, mariscal de campo y gobernador de la ciudad de Alicante. Éste figura en siete ocasiones como "requisador" de los buques, aunque a la hora de referirse al fletador el documento menciona al tantas veces aludido Driguet. Asimismo en la práctica totalidad de los casos la requisa se produce en aguas alicantinas. Unicamente hay cinco excepciones en la que aquélla tuvo lugar en Cartagena, dando lugar a situaciones muy tensas posteriormente reflejadas en las correspondientes escrituras de protesta ante notario al llegar a mediar entre la requisa y la firma del contrato de fletamento más de un mes $^{28}$.

Dejando de lado lo traumático que resultaba ser objeto de un embargo, lo cierto es que el tratamiento para los embargados o fletantes solía ser bastante favorable desde el punto de vista económico. Así, ya se ha indicado con anterioridad que el flete mensual se establecía a razón de tres pesos por tonelada de arqueo, cantidad que debía hacerse efectiva siempre por meses adelantados. Al margen de ello, a la hora de la firma del contrato se incluía junto a la primera mensualidad el pago, por una sola vez, de la denominada capa, esto es, el $10 \%$ del valor mensual del flete. Ello quiere decir que el capitán de un navío, pongamos por caso, de 500 toneladas percibía en el momento de concretar el fletamento 1.650 pesos: 1.500 correspondían a la primera mensualidad y los restantes 150 eran en concepto de capa. Junto a la exención de pago de todo tipo de derechos portuarios en los muelles españoles, a los capitanes de los navíos fletados se les aseguraba la percepción de una indemnización en caso de pérdida. siempre y cuando la misma fuera imputable a acciones o efectos derivados del Real Servicio.

Los mayores problemas surgían cuando los barcos incautados portaban mercancías. En esos casos se establecían las correspondientes compensaciones por la descarga de las mismas y su embarque en otros buques o, simplemente, por su pérdida si es que se trataba de

27 Con posterioridad Francisco Driguet, marqués de Malespina, desempeñaría puestos de responsabilidad en la administración española. Así, entre el 31 de diciembre de 1741 y el 4 de abril de 1754 ocupó el cargo de Intendente-corregidor de la ciudad de Valencia convirtiéndose de hecho, y pese sus abundantes ausencias por los requerimientos de la corte, en la persona que durante más tiempo se mantuvo en este empleo; ver E. GIMÉNEZ LóPEZ: Militares en Valencia (1707-1808). Los instrumentos del poder borbónico entre la Nueva Planta y la crisis del Antiguo Régimen. Instituto de Cultura "Juan Gil-Albert". Alicante, 1990, pp. 135-136. Ver asimismo C. CORONA MARZOL: "Los militares y la administración provincial: Intendentes y Contadores del Ejército en la Valencia del siglo XVIII", o en Temas de Historia Militar. Zaragoza 1986. Vol. I, pp. 428-445.

28 Se trata de cinco navíos, cuatro de nacionalidad inglesa y uno francés. Éste último, denominado "San Francisco" y capitaneado por Pedro Sandoure fue apresado en Cartagena el día uno de enero de 1718, pero no hay acta de fletamento en Alicante hasta un mes más tarde (AHPA. Protocolos notariales de Francisco Andújar, P/65, ff. 54-55v). Los restantes son los siguientes navíos ingleses: "Leal súbdito" y "La galera Sara", cuyos capitanes Diego Porter y Guillermo Finlanzon declaran el 11 de enero de 1718 que sufrieron el embargo en Cartagena el 27 de diciembre de 1717 (AHPA. Protocolos notariales de Antonio García, P/785, ff. 11-12v y 13-14v), e idéntica declaración hallamos en Joseph Sandwell, capitán del "Aurengzeb", y Juan Fearing, capitán de "El águila", fletados respectivamente el 18 de marzo y 21 de abril tras ser interceptados un mes antes (AHPA. Protocolos notariales de Antonio Garcia, P/785, ff. 60-61v y 127-128v). 
mercancías perecederas. La documentación no suele ser muy explícita en este sentido y aunque, en general, se refiere a "mercancías" en abstracto, ocasionalmente sí indica el objeto y misión de la travesía del barco requisado. Así, por ejemplo, al capitán francés Claudio Polí se le embargó su navío "San Antonio", de 608 toneladas, cuando había arribado a Alicante presto a cargar sal, presumiblemente de las salinas de La Mata ${ }^{29}$. Jorge Meafield, capitán del navío inglés "La Paz" requisado el 22 de febrero de 1718 , refiere que transportaba sardina; idéntica carga a la portada por el también inglés Juan Fearing en su navío "El águila". En el primer caso, una indemnización sirvió para aplacar las iras del capitán. Por lo que hace a Fearing, la imposibilidad de éste de colocar en Alicante, por estar la plaza muy bien abastecida, el salazón que llevaba con destino a Venecia provocó gran tensión al trasladar el inglés a don Francisco Driguet la responsabilidad de la pérdida de la carga $^{30}$. Otros capitanes o patrones especifican que transportan lana, toneles de vino ${ }^{31}$, e incluso trigo en tránsito desde Amsterdam a Génova ${ }^{32}$.

Al margen de estos casos concretos, la realidad es que el fletador procuró salvar, y al parecer lo consiguió las más de las veces, situaciones similares a las reseñadas. Para ello arbitró una fórmula de compensación o indemnización económica en función de la carga transportada, los costes de su desembarco y los derivados de la colocación de la misma en manos de otros mercaderes al objeto de que no se perdiera. En ese sentido se hallan referencias al pago de cantidades que oscilan entre los 20 y los 200 pesos y los 11 y los 151 reales de vellón, según los casos. Las compensaciones más elevadas se refieren a los navíos incautados en Cartagena y trasladados a Alicante para concertar el fletamento ${ }^{33}$. Respecto de esta cuestión de las indemnizaciones existe una declaración expresa de Francisco Driguet, fechada el 16 de febrero de 1718, en la que manifiesta que, hasta esa fecha, se había abonado a todos los capitanes y patrones los gastos derivados del desembarque y subsiguiente embarque de las mercancías que transportaban. Al recibir quejas por parte de Lorenzo Peretí, capitán del navío francés "San Miguel", en el sentido de habérsele discriminado en esta compensación, dispuso el inmediato abono de 20 libras y un sueldo, importe de la descarga de los fardos de lana y otras mercancías que portaba ${ }^{34}$.

La cronología de la actividad fletadora desplegada en Alicante como consecuencia de la expedición a Sicilia se puede establecer con toda exactitud. Así, las 58 actas de fletamento tienen lugar entre los meses de enero y mayo del año 1718, correspondiendo el mayor flujo al mes de febrero. El día 11 de enero de ese año fueron fletados los cuatro primeros barcos,

29 AHPA. Protocolos notariales de Francisco Andújar, P/65, ff. 58-59v.

30 AHPA. Protocolos notariales de Francisco Andújar, P/65, ff. 96-97v y Protocolos notariales de Antonio Garcia, P/785, ff. 132-132v.

31 Es el caso de Juan Chave, patrón de la tartana "San Juan Bautista", quien se compromete a descargar por tres pesos extra "todo el piperío que tenía a bordo", AHPA. Protocolos notariales de Antonio García, $\mathrm{P} / 785$, ff. $172-173$.

32 Así lo refiere el inglés Joseph Sandwell, capitán del "Aurengzeb", al promover una enconada protesta ante el fletador tras sentirse gravemente afectado en sus intereses; AHPA. Protocolos notariales de Antonio García, P/785, ff. 37-38.

33 Ver nota 28.

34 AHPA. Protocolos notariales de Francisco Andújar, P/65, ff. 82-82v. 
todos ellos ingleses y, por ende, procedentes de Cartagena donde habían sido requisados el 27 de diciembre del año anterior ${ }^{35}$. El mes de febrero contempló el fletamento de 22 embarcaciones, de las que doce -en su mayoría inglesas- suscribieron el contrato el día 22. Marzo fue un mes tranquilo, semejante a enero, con tan sólo cinco escrituras; mientras que entre el 4 de abril y el 30 de mayo se alcanzaba la cifra de 27 fletamentos completando, de ese modo, el total de 58 que se dirigieron de manera paulatina al puerto de Barcelona para, desde allí, zarpar hacia Sicilia.

Mensualmente el flete de estos navíos surtos en Alicante representaba para la hacienda española un gasto de 41.752 pesos, a una media de 720 pesos por barco y mes, todo ello sin contar el estricto mantenimiento de las tripulaciones. En lo tocante a las indemnizaciones estipuladas en caso de que los barcos fueran hundidos, éstas representaban la bonita suma de 315.700 pesos, por lo que no estaría de más comprobar si ello fuera posible los efectos que sobre los barcos fletados -no ya solo en Alicante, sino en toda la costa mediterránea española- causó la acción del almirante Bingg frente al cabo Passaro. A título meramente ilustrativo ofrecemos un cuadro en el que se contienen los navíos con fletes e indemizaciones más elevados.

\begin{tabular}{lccccc}
\hline NOMBRE & NACION & TIPOLOGIA & TONELAJE & $\begin{array}{c}\text { FLETE/MES } \\
\text { (pesos) }\end{array}$ & $\begin{array}{c}\text { INDEMNIZACION } \\
\text { (pesos) }\end{array}$ \\
\hline San Nicolás & Franc. & Navío & 634 & 1.902 & 10.900 \\
San Francisco & Franc. & Navío & 613 & 1.813 & 12.000 \\
Mediterráneo & Ingl. & Navío & 400 & 1.200 & 10.500 \\
Santiago & Genov. & Navío & 357 & 1.071 & 10.000 \\
Prínc. Jorge & Ingl. & Navío & 347 & 1.038 & 10.000 \\
El Fénix & Franc. & Navío & 342 & 1.023 & 12.000 \\
\hline
\end{tabular}

\section{CUADRO V.- FLETES E INDEMNIZACIONES MAS ELEVADOS (1718)}

En torno a las expediciones italianas gravitaron intereses muy variados e, igualmente, se plantearon necesidades que satisfacer desde el punto de vista infraestructural y de intendencia. Por ello no resulta extraño encontrar referencias concretas sobre aspectos tales como el transporte de tropas y pólvora -cuando la norma general en los fletamentos analizados era ignorar el destino del buque y su misión- tanto antes como después de la salida de la expedición a Sicilia, así como ciertos encargos a particulares e incluso a gremios de la ciudad; encargos que tenían mucho que ver con la mejora del material bélico y el acomodo de víveres y animales.

35 Ver nota 28. 
Así, entre los meses de julio y diciembre de 1718 -por tanto, cuando la flota ya ha partido del puerto de Barcelona-, hemos detectado la requisa de siete buques, todos franceses y de diferentes portes para emplearlos, fundamentalmente, en el transporte de pólvora desde Alicante a Barcelona y Palma de Mallorca ${ }^{36}$. En todos los documentos fígura como fletador el gobernador de Alicante, don Antonio José Chaves o, en su defecto, el alcalde mayor, don Francisco Esteban Zamora, siendo los receptores don Rodrigo Caballero, a Ia sazón Intendente General de Cataluña tras sustituir en el cargo a don José Pedrajas ${ }^{37}$, y el marqués de Casafuerte, comandante general de la isla de Mallorca. Se trata de barcos artillados y con tripulaciones a bordo que oscilan entre los diez y los veinte hombres.

Al socaire de la actividad fletadora se concertaron ciertos pedidos interesantes para la economía local, por cuanto significaban un incremento en actividades de producción discreta o muy limitada. Así tenemos constancia de ciertas obligaciones contraídas con la Real Hacienda, algunas de ellas anteriores a 1718. En esta situación se hallaba Damián Torregrosa, armero alicantino, quien en agosto de 1716 reconocía tener un convenio con don Francisco Sánchez Pedraza, Comisario de Guerra en la plaza, para la "recomposición" de 402 fusiles y 30 pares de pistolas. Se le daba un plazo de seis meses para acabar su tarea, a la vez que se establecía un pago de 185 libras 14 sueldos y 6 dineros ${ }^{38}$.

También hemos hallado el compromiso adquirido el cuatro de enero de 1718 ante don Francisco Driguet por el carpintero Gaspar Palomares de "aver de hazer a bordo y baxo cubierta de los navíos que se le señalarán, de una hasta ochocientas caballerizas según la planta que para este efecto se le ha ajustado"39. Estas caballerizas posibilitarían el transporte de 3.200 animales, y su construcción suponía un gasto total de 48.000 reales de vellón. Incluso el gremio de cordeleros de la ciudad de Alicante reconoció tener un convenio con el tantas veces citado Driguet para elaborar 2.000 sacos de cáñamo con capacidad cada uno de ellos de fanega y media, además de 800 camas para caballos y 30 cinchas maestras; todo ello por un monto total de 32.900 reales de vellón ${ }^{40}$. Actuaciones de este tipo no fue-

36 Se rata de la urca "San Nicolás", de 650 toneladas; de las galeras "Volante" y "Amable", de 110 y 300 toneladas rspectivamente; del pingue "San Antonio", de 180 toneladas; de la tartana "San José", de 70 toneladas y de los gánguiles "San José" y "San Juan", de 70 y 40 toneladas cada uno. Cifr. en AHPA. Protocolos notariales de Antonio García, P/785, ff. 224-226, 254-255, 256-257, 261-261, 351-352, 358$359 \mathrm{v}$ y $37 \mathrm{I}-372$.

37 J. MERCADER RIBA: Felip V..., pág. 145. En torno a la actividad desplegada por Pedrajas y Rodrigo Caballero en Valencia ver H. KAMEN: La Guerra de Sucesión en España. 17(0)-1715. Barcelona, 1974, pp. 337 y s.

38 El pago se desglosaba de la siguiente manera:

- 120 libras 10 sueldos y 3 dineros por el arreglo de 311 fusiles, a razón de 7 sueldos 9 dienros por fusil

54 libras 12 sueldos asimismo por el arreglo de los restantes 91 fusiles

- 15 libras por la reparación de los 30 pares de pistolas.

Según esto, la cantidad total a percibir por el armero alicantino ascendería a 190 libras 2 sueldos y 3 dineros, pero al deducirse dos cuartos por escudo para inválidos restaban líquidas las 185 libras 14 sueldos y 6 dineros indicadas. Cifr. en AHPA. Protocolos notariales de Antonio García, P/783, ff. 171-172.

39 AHPA. Protocolos notariales de Antonio Garcia. P/785, ff. 1-12.

40 AHPA. Protocolos notariales de Antonio Garcia, P/785, ff. 3-4. Los precios unitarios eran, respectivamente, 4,25 y 30 reales de vellón. 
ron desconocidas en los círculos catalanes, antes bien fueron alentadas, y con posterioridad las volveremos a encontrar en la misma ciudad de Alicante como consecuencia de la expedición contra Orán del año $1732^{41}$.

\section{LA OPOSICION DE LOS CAPITANES AL EMBARGO Y LA ACTITUD DE LAS COMPAÑIAS COMERCIALES ESTABLECIDAS EN ALICANTE}

Obviamente los embargos de buques no fueron aceptados de buen grado por la gran mayoría de los capitanes quienes, con mayor o menor rigor, mostraron su descontento e indignación. Los capitanes ingleses fueron los que con más vehemencia hicieron constar su disgusto, dando lugar a tensas situaciones que nos transmiten de manera fidedigna los protocolos notariales. No es difícil imaginar la reacción de los afectados cuando, en el momento del atraque de su barco se les comunicaba la decisión del director de la expedición de reclamar el mismo para dedicarlo al Real Servicio. Desconocedores en muchos casos del idioma, portadores de mercancías con destino a lugares más alejados de las costas levantinas y al servicio de intereses comerciales muy concretos, los capitanes no se conformaban con facilidad por lo que, reiteradamante, hubo que recurrir a la coacción ${ }^{42}$. Así, por ejemplo y aunque ya se haya hecho mención páginas atrás, Josep Sandwell, capitán del navío ingles "Aurengzeb", describe cómo le fue embargado éste en Cartagena y obligado a dirigirse al puerto de Alicante so pena de 2.000 pesos. En su momento hizo constar en la propia Cartagena el grave perjuicio que le representaba no poder entregar en Génova el trigo que transportaba desde Amsterdam. Llegado a Alicante reiteró su protesta ante el notario, aunque ello no le valiera de nada puesto que no le quedó más alternativa que ponerse a las órdenes de Francisco Driguet ${ }^{43}$. Muy similar es el caso de Juan Fearing, igualmente inglés y capitán del navío "El Aguila", quien desde Inglaterra transportaba sardina y otros géneros con destino al puerto de Venecia. Los vientos contrarios y el mal tiempo reinante le obligaron a refugiarse en Cartagena el veinte de marzo de $1718 \mathrm{y}$, de inmediato, el gobernador de la plaza procedió al embargo del navío y a la detención de su capitán. Enviado por tierra a Alicante custodiado por dos soldados se obligó, bajo multa de 2.000 pesos, a que su piloto trajera el barco hasta el puerto alicantino para ponerse al servicio de Driguet. Hasta la llegada del buque estuvo preso en casa de los comerciantes ingleses Jaime Blechley y Jorge Hammond, titulares de la Compañía Comercial de idéntico nombre. En este caso el capitán Fearing, además de sufrir el embargo del buque y la detención personal, perdió todo el género que portaba puesto que Alicante se hallaba convenientemente abastecida de sardina ${ }^{44}$. Se podría espigar más situaciones parecidas, pero no lo creemos necesario habida cuenta de que las señaladas ilustran sobradamente tanto del desasosiego que se apoderaba de los responsables de los navíos fletados, como de las pérdidas económicas que la acción les solía acarrear.

41 J. MERCADER RIBA: Felip V..., pp. 206 y ss. A. ALBEROLA ROMA': "El port d'Alacant...". 42 Situaciones de este tipo las describe J. MERCADER RIBA: Felip V..., pág. 220, nota 358.

43 AHPA. Protocolos notariales de Antonio García, P/785, ff. 37-38.

44 AHPA. Protocolos notariales de Antonio García, P/785, ff. 132-132v. 
Pero una vez consumados los hechos, buena parte de los capitanes ingleses pretendieron preservar sus intereses. En consecuencia procuraron asegurarse la percepción mensual del flete y, en su caso, la correspondiente indemnización por la pérdida del navío. Para ello recurrieron a intérpretes, generalmente de su misma nacionalidad y que les merecieran su confianza, al objeto de que las cláusulas contenidas en las actas de fletamento no les fueran lesivas. Con posterioridad otorgaron plenos poderes a particulares o a compañías comerciales de compatriotas establecidas en Alicante para que velaran por sus intereses e hicieran cumplir lo pactado ante el notario. Es por ello que resulta habitual encontrar, tras la escritura de fletamento, otra en la que el capitán del buque afectado concede el correspondiente poder.

De los cincuenta y ocho navíos fletados, los responsables de treinta y dos recurrieron al empleo del poder. De ellos, veintiuno eran ingleses por sólo tres franceses. La totalidad de los primeros precisaron de intérprete, tanto en el momento de la requisa del buque como a la hora del otorgamiento de poderes, aunque en ningún caso responden a las mismas personas en una y otra escritura. En el primer caso, esto es a Ia firma del fletamento, figuran siempre comerciantes de su misma nacionalidad, mientras que en el acta de poder da la impresión de que se recurre a individuos de cierta cualificación, bien sea a nivel político o bien a nivel profesional. 


\begin{tabular}{|c|c|c|}
\hline Pedro Sandoure & Francesa & navío \\
\hline Jaime de Laye & Francesa & navío \\
\hline Francisco Rubin & Francesa & navío \\
\hline Diego Talbot & Inglesa & urca \\
\hline Thomas Vermoth & Inglesa & navío \\
\hline Jorge Meafield & Inglesa & navío \\
\hline Juan Young & Inglesa & navío \\
\hline Guillermo Waren & Inglesa & navío \\
\hline Nathaniel Colbey & Inglesa & navío \\
\hline Arthur Ballard & Inglesa & navío \\
\hline Ricardo Langley & Inglesa & navío \\
\hline Guillermo Morshead & Inglesa & navío \\
\hline Mordecay Evans & Ingleas & navío \\
\hline Enrique Winfield & Inglesa & navío \\
\hline Guillermo Finlanzon & Inglesa & navío \\
\hline Juan Rey & Inglesa & navío \\
\hline Abraham Howard & Inglesa & navío \\
\hline Joseph Sandwell & Inglesa & navío \\
\hline Guillermo Atturod & Inglesa & navío \\
\hline Benjamin Cloyes & Inglesa & navío \\
\hline Ricardo Loveell & Inglesa & navío \\
\hline Elías Hudd & Inglesa & navío \\
\hline Eduardo Downing & Inglesa & navío \\
\hline Juan Barclay & Inglesa & navío \\
\hline Juan Saunders & Inglesa & navío \\
\hline Juan Fearing & Inglesa & navío \\
\hline Ricardo Pim & Inglesa & navío \\
\hline Jaime Sawdon & Inglesa & navío \\
\hline Edmond Adams & Inglesa & navío \\
\hline John Corne & Inglesa & navío \\
\hline Samuel Rodham & Inglesa & navío \\
\hline Juan Hampton & Inglesa & navío \\
\hline
\end{tabular}

CUADRO VI.- RELACION DE CAPITANES QUE OTORGARON PODERES (1718) 
Son los comerciantes ingleses Jaime Blechley, Samuel Tucar y Salomon Merret quienes, con mayor asiduidad, sirven de intérprete a sus compatriotas en el instante de estipularse las condiciones del fletamento ${ }^{45}$. Sin embargo en la escritura de poder ya no aparecen éstos sino otros personajes. Entre ellos destaca el inglés Benjamín de Lafontaine, con catorce actuaciones como traductor; el español Pedro Benesiu, con cinco; el vicecónsul inglés Thomas Corson, en cuatro ocasiones, y los ciudadanos de la misma nacionalidad Samuel Keay y Ezequiel Hall, una sola vez. Todas las escrituras de poder contienen, en esencia, las mismas cláusulas aunque con mayor o menor lujo de detalles según los casos. Básicamente, y tras hacer constar el poderdante que ha sido obligado a signar el fletamento, nombra como procurador a una Compañía Comercial ${ }^{46}$ de su misma nacionalidad para que

"pida, demande y cobre del pagador, tesorero o/y otra cualesquier persona que se destinare por la Rl. Hacienda (...) todo quanto se causare, devengare o deviere a dicho otorgante por razón del flete del dicho su navío todo el tiempo que estuviesse empleado en el Real Servicio para lo qual ha sido embargado $(\ldots)$.

Caso de que las pagas mensuales acordadas no se percibieran puntualmente se hace constar que "si necesario fuere, comparezca [el procurador] ante su magestad, señores superintendentes, oficiales y ministros de la guerra, ante quien convenga, y pida se le despachen los correspondientes libramientos". Pero junto a estos mandatos para cobrar judicial o extrajudicialmente las cantidades acordadas en concepto de flete e indemnización, también se dan las instrucciones pertinentes para despachar las mercancías transportadas hasta el momento de la requisa y obtener un beneficio económico; beneficio que quedaba bajo la custodia de las correspondientes compañías comerciales. La actividad de éstas, por lo que a actuaciones como apoderados se refiere, se refleja en el siguiente cuadro, en el que se observa que quienes en su momento actuaron como traductores en el difícil momento de la legalización del fletamento aparecen ahora como representantes de los capitanes de los navíos incautados por la Real Hacienda. Quizá la primera actuación, posiblemente desinteresada, justifique la concesión de poderes para actuar como "cobradores"; acción que debía de reportarles algún beneficio económico como es lógico pensar.

45 Blechley figura como traductor en catorce ocasiones, Tucar en seis y Merret en cinco. Aparecen una sola vez Juan Lapaiese, de nacionalidad inglesa, y Gerónimo de la Vega, Comisario General de Artillería.

46 En torno a las Compañías Comerciales radicadas en el antiguo reino de Valencia ver R. FRANCH BENAVENT: Crecimiento comercial y enriquecimiento burgués en la Valencia del siglo XVIII. Valencia, 1986; fundamentalmente las páginas 241 y ss. Respecto a los comeciantes extranjeros establecidos en la ciudad de Alicante, ver E. GIMÉNEZ LóPEZ: Alicante en el siglo XVIII..., pp. 237-247. 


\section{Blechley y Hammond}

Blech, Tucar y Blech

Salomon Merret y Cia.

Herney, Blahely y Hammond

Bruges y Antoine

Carlos Choly y Cia.

$\begin{array}{cr}\text { Inglesa } & 14 \\ \text { Inglesa } & 9 \\ \text { Inglesa } & 5 \\ \text { Inglesa } & 2 \\ \text { Francesa } & 1 \\ \text { Francesa } & 1\end{array}$

\section{CUADRO VII.- COMPAÑIAS COMERCIALES QUE OBTUVIERON PODE- RES PARA COBRAR FLETES}

\section{CONSIDERACIONES FINALES}

Hasta aquí los pormenores relativos a la preparación de la expedición destinada a reconquistar Sicilia. Los sucesos posteriores son bien conocidos: desembarco en Palermo y fácil ocupación de la isla en colaboración con los propios sicilianos. Sin embargo la respuesta internacional, con la firma de la Cuádruple Alianza, y la acción militar del almirante Byngg en el cabo Passaro contra una desordenada armada hispana ${ }^{47}$ propiciaron un giro radical de los acontecimientos que no es nuestro objetivo comentar. Sin embargo sí cabe efectuar algunas reflexiones relativas tanto a la fuente manejada como a las posibilidades que, en su momento, ofreció el fletamento a los organizadores de las flotas con destino a las plazas italianas. El análisis de los fletamentos, y por ende de las escrituras que tienen relación estrecha con los mismos, permite obtener un número importante de variables que contribuye a dimensionar los preparativos de las expediciones. Obviamente el aparato desplegado por Patiño fue, desde todo punto, espectacular y complejo, no limitándose a la mera construcción o compra de buques, empresa esta que requería tiempo y más medios. Así, el importante tráfico marítimo existente en los puertos del Mediterráneo español permitió al, por entonces, Intendente General de Marina aprovechar las posibililidades que le brindaba el gran número de buques que entre ellos circulaban y atracaban. Su requisa, utilizando el recurso del fletamento, solventó los problemas de transporte y minimizó relativamente las carencias. Es evidente que ello supuso un considerable costo económico, pero

47 El juicio del marqués de San Felipe en relación con la derrota española es ciertamente duro al afirmar: "Esta es la derrota de la armada española, voluntariamente padecida en el golfo de Ariaich, canal de Malta, donde sufrió un combate sin línea ni disposición militar, atacando los ingleses a las naves españolas a su arbitrio, porque estaban divididas. No fue batalla sino un desarreglado combate que redunda en mayor desdoro de la conducta de los españoles, aunque mostraron imoponderable valor, más que los ingleses que nunca quisieron abordar por más que lo procuraron los españoles"; cifr. en Comentarios ..., pág. 292. Sin embargo, este juicio no puede hacernos olvidar las sutiles maniobras desplegadas por Byngg y la incómoda posición que ocupaba la flota española tal y como describe Coxe en España bajo el reinado ..., II, pp. 239241. 
la empresa lo requería y los recursos se aprontaron. El ejemplo de lo acaecido en Alicante quizá pueda seguirse también en otros lugares, a semejanza de lo que hizo Mercader Riba para Cataluña. Un análisis detallado arrojaría luz sobre estas cuestiones tan sugerentes relativas al hallazgo de alternativas que permitieron suplir las evidentes carencias navales de la monarquía hispánica tras la Guerra de Sucesión; hasta el punto de que la actitud española llegó a asombrar y, por supuesto, a preocupar al resto de potencias europeas ${ }^{48}$. Queda en el aire el destino final de los buques extranjeros fletados, ya que ignoramos si todos ellos regresaron de la expedición o si, por contra, sufrieron los embates de la guerra o de los elementos. No parece que ninguno de éstos participara en la batalla del cabo Passaro, con lo que las indemnizaciones no se harían efectivas. También desconocemos si la Real Hacienda fue una cumplidora fiel de sus compromisos monetarios. En cualquier caso no tenemos constancia de reclamación por parte de las compañías comerciales encargadas de velar por los intereses de los buques fletados. No obstante, todo este entramado jurídicoeconómico surgido al socaire de estas empresas bélicas del primer borbón debe ser tenido muy en cuenta. $Y$ hay un hecho innegable: el sistema funcionó. Tanto es así que, como se indicó al principio del trabajo, el fletamento-requisa de buques desempeñó un importante papel a la hora de concebir empresas posteriores.

48 "Las grandes potencias de Europa vieron con asombro que España, como el león, emblema de sus armas, despertaba tras de un siglo de letargo desplegando un vigor y una firmeza digna de los más hermosos días de la monarquía, haciendo temer que se renovase una guerra a que apenas acababa de poner término el tratado de Utrech", G. COXE: España bajo el reinado ..., II, pág. 234. 


\begin{tabular}{|c|c|c|c|c|}
\hline FECHA & EMBARCACION* & CAPITAN** & $\begin{array}{l}\text { FLETE/MES } \\
\text { (PESOS) }\end{array}$ & $\begin{array}{l}\text { INDEMNIZACION } \\
\text { (PESOS) }\end{array}$ \\
\hline $11-1-18$ & Shrewbury (U) & D. Talbot (I) & 1.500 & 7.000 \\
\hline $11-1-18$ & Leal Súbdito (N) & D. Porter (I) & 600 & 6.000 \\
\hline $11-1-18$ & Sara Gales (N) & G. Finlanzon (I) & 612 & 6.000 \\
\hline $11-1-18$ & Elton $(\mathrm{G})$ & J. Hall (I) & 675 & 7.500 \\
\hline $6-2-18$ & San Francisco $(\mathrm{N})$ & P. Sandoure (F) & 1.813 & 12.000 \\
\hline $6-2-18$ & El Fénix (N) & J. Hubert (F) & 1.023 & 12.000 \\
\hline $6-2-18$ & San Antonio (N) & C. Poli (F) & 1.842 & 8.000 \\
\hline $8-2-18$ & Santiago (N) & F. Parodi $(G)$ & 1.071 & 10.000 \\
\hline $8-2-18$ & San Miguel (N) & L. Peretti (F) & 1.014 & 7.500 \\
\hline $8-2-18$ & N. Sa. Rosario (N) & J. Bta. Agnesi (G) & 840 & 8.000 \\
\hline $9-2-18$ & S. Juan Bta. (B) & J.Bta. Brive (F) & 426 & 3.000 \\
\hline $9-2-18$ & La Francisca (N) & F. Brignon (F) & 690 & 7.000 \\
\hline $11-2-18$ & $\operatorname{Kesia}(\mathrm{N})$ & T. Venmoth (I) & 705 & 7.000 \\
\hline $22-2-18$ & $\operatorname{LaPaz}(\mathrm{N})$ & J. Meafield (I) & 909 & 7.000 \\
\hline $22-2-18$ & $\operatorname{Ana}(\mathrm{N})$ & J. Young (I) & 525 & 4.000 \\
\hline $22-2-18$ & G. de Florencia (N) & G. Waren (I) & 579 & 5.000 \\
\hline $22-2-18$ & Príncipe Gales (N) & N. Colbey (I) & 774 & 4.700 \\
\hline $22-2-18$ & La Deseada $(\mathrm{G})$ & A. Ballard (I) & 639 & 5.800 \\
\hline $22-2-18$ & Honor $(\mathrm{N})$ & R. Langley (I) & 414 & 3.400 \\
\hline $22-2-18$ & Mercader Lisboa (N) & J. Clark (I) & 585 & 3.900 \\
\hline $22-2-18$ & Galera Lyne (N) & G. Morshead (I) & 741 & 4.800 \\
\hline $22-2-18$ & Griffon $(N)$ & M. Evans (I) & 525 & 4.100 \\
\hline $22-2-18$ & Merc. Hamburgo (N) & E. Winfield (I) & 702 & 5.000 \\
\hline $22-2-18$ & La Esperanza (N) & J. de Laye (F) & 456 & 3.500 \\
\hline $22-2-18$ & San Nicolás (N) & J. Borely & 1.902 & 10.900 \\
\hline $25-2-18$ & S. Juan Evang. (N) & L. Gante (F) & 564 & 3.500 \\
\hline $2-3-18$ & Abraham (N) & J. Rey (I) & 741 & 4.500 \\
\hline $3-3-18$ & Príncipe Jorge $(\mathrm{N})$ & J. Hampton (I) & 1.038 & 10.000 \\
\hline $4-3-18$ & Britannia (N) & A. Howard (I) & 531 & 5.000 \\
\hline $6-3-18$ & San Nicolás (U) & J. Borrell (F) & 1.500 & 7.000 \\
\hline $18-3-18$ & Aurengzeb $(\mathrm{N})$ & J. Sandwell (I) & 756 & 5.600 \\
\hline $4-4-18$ & Bedminster (N) & G. Atturod (I) & 696 & 6.000 \\
\hline $4-4-18$ & Burcam (N) & B. Cloyes (I) & 588 & 3.500 \\
\hline $4-4-18$ & Pedro y felipe $(\mathrm{N})$ & R. Loveell (I) & 978 & 7.000 \\
\hline $7-4-18$ & El Frod (N) & E. Hudd (I) & 987 & 6.000 \\
\hline $7-4-18$ & La Paz (N) & J. Chubb (I) & 348 & 3.000 \\
\hline $7-4-18$ & Pequeño Rubí (N) & E. Downing (I) & 297 & 3.000 \\
\hline $9-4-18$ & El Constante $(\mathrm{N})$ & H. Ginnons $(F)$ & 768 & 6.500 \\
\hline $10-4-18$ & Hanmore $(\mathrm{N})$ & J. Potter (I) & 297 & 1.500 \\
\hline
\end{tabular}




\begin{tabular}{rcccc}
\hline FECHA & EMBARCACION* & CAPITAN** & $\begin{array}{c}\text { FLETE/MES } \\
\text { (PESOS) }\end{array}$ & $\begin{array}{c}\text { INDEMNIZACIO } \\
\text { (PESOS) }\end{array}$ \\
\hline $14-4-18$ & Plymouth (N) & J. Saunders (I) & 840 & 7.000 \\
$18-4-18$ & La María (N) & J. Barclay (I) & 846 & 5.500 \\
$21-4-18$ & El Aguila (N) & J. Fearing (I) & 924 & 6.500 \\
$23-4-18$ & San Juan (N) & J. Caudier (F) & 942 & 8.000 \\
$25-4-18$ & Mediterráneo (N) & R. Pim (I) & 1.200 & 10.500 \\
$27-4-18$ & Reina Indiana (N) & J. Sawdon (I) & 471 & 3.500 \\
$9-5-18$ & Blake (N) & E. Adams (I) & 555 & 5.000 \\
$9-5-18$ & Sta. María (N) & L. Alignan (F) & 1.473 & 8.200 \\
$9-5-18$ & S. Juan Bta. (N) & F. Rubín (F) & 1.044 & 8.000 \\
$9-5-18$ & N.S.Misericordia (P) & A. Parou (F) & 342 & 3.000 \\
$9-5-18$ & Santa Ana (P) & C. Lunes (F) & 219 & 2.000 \\
$13-5-18$ & S. Juan Bta. (T) & J. Chave (F) & 174 & 1.000 \\
$16-5-18$ & San Juan (T) & J. Guedieu (F) & 195 & 1.200 \\
$16-2-18$ & San José (T) & P. Chapus (F) & 159 & 1.000 \\
$21-5-18$ & Santa Isabel (T) & L. Blay (F) & 150 & 1.000 \\
$27-5-18$ & Espíritu Santo (T) & J. Cornau (F) & 174 & 1.000 \\
$30-5-18$ & San Antonio (T) & A. Hervin (F) & 174 & 1.100 \\
$30-5-18$ & María Juana (N) & S. Rodham (I) & 393 & 2.000 \\
\hline & & & & \\
\hline
\end{tabular}

RELACION DE LAS EMBARCACIONES FLETADAS EN ALICANTE PARA EMPLEARLAS EN EL REAL SERVICIO DURANTE EL AÑO 1718, CON EXPRESION DESUS CAPITANES, Y LOS VALORES DEL FLETE E INDEMNIZACIóN.

* = entre paréntesis figura la tipología del barco según las siguientes claves: $N=$ navío, $U=$ urca, $\mathrm{G}=$ galera, $T=\operatorname{tartana}, P=$ pingue, $B=$ barca.

$*:=$ entre paréntesis figura la nacionalidad de los capitanes según las siguientes claves: $F=$ francesa, $I=$ inglesa, $\mathrm{G}=$ genovesa. 